\title{
APPLICATION OF INTUITIONISTIC FUZZY TOPSIS MODEL FOR TROUBLESHOOTING AN OFFSHORE PATROL BOAT ENGINE
}

\author{
Daniel Osezua Aikhuele, MSc $^{1}$ \\ Shahryar Sorooshian, $\mathrm{PhD}^{2}$ \\ Richard Hannis Ansah, $\mathrm{MSc}^{3}$ \\ Faiz Mohd Turan, $\mathbf{P h D}^{4}$ \\ ${ }^{1,4}$ Faculty of Manufacturing Engineering, Universiti Malaysia Pahang, Malaysia \\ ${ }^{2,3}$ Faculty of Industrial Management, Universiti Malaysia Pahang, Malaysia
}

\begin{abstract}
In this paper, an Intuitionistic Fuzzy TOPSIS model which is based on a score function is proposed for detecting the root cause of failure in an Offshore Boat engine, using groups of expert's opinions. The study which has provided an alternative approach for failure mode identification and analysis in machines, addresses the machine component interaction failures which is a limitation in existing methods. The results from the study show that although early detection of failures in engines is quite difficult to identify due to the dependency of their systems from each other. However, with the Intuitionistic Fuzzy TOPSIS model which is based on an improved score function such faults/failures are easily detected using expert's based opinions.
\end{abstract}

Keywords: Intuitionistic Fuzzy TOPSIS model; improved score function; MCDM; detecting early failure; Offshore Patrol Boat Engine

\section{INTRODUCTION}

Many of the modern developed machines are required to run under increased turbulent conditions and in some cases under uncertainty [1], and since it is the goal of every maintenance, the strategy is to avoid the high cost of maintenance and production risks due to the rotating machine's fault [2]. It is therefore of great importance that the machines are precisely assessed and tested (troubleshooted) for failure to see if they meet the business's objectives before they are moved forward. According to Zuber \& Bajri [2], 'monitoring the health of machines through the implementation of condition-based maintenance strategy is based on the acquisition and trending of the physical parameter that is found to be sensitive to machine degradation' and failure.

Failure warnings and measures such as heating, pressure, and flow rate sensors as well as vibration measurement and analysis, motor current signature analysis, noise measurement, wear particle analysis, infrared thermography and ultrasound measurements devices are available and often used to detect and monitor possible failures in machines. Expert's decisions on the failure of the machine are then taken based on the values of the indicators which reflect the failure in the existing guidelines. However, according to Balin et al., [3], even if the warning indicators values and alarms from such machines are taken into account, early detection of such failures are still quite difficult to determine because of the dependency of the machine systems from each other. Also, even with the innovative computer-based generated fault diagnosis systems available, 'the fault codes don't always pinpoint the exact problem but rather bring up an array of codes that could be either this or that'.

The traditional alternative methods used for Product Development Failure Mode identification such as Failure Mode and Effect Analysis (FMEA) and Fault Tree Analysis [4] which have been used for potential failure modes and failure analysis in new machine systems, are also limited 
when it comes to design errors, human factors implications, flawed requirements and component interaction accidents and failures [5], [6].

To handle this kind of problem, an intuitionistic fuzzy multi-criteria decision-making method is suggested. The fuzzy Shannon's entropy (FSE) method is adopted in an Intuitionistic Fuzzy TOPSIS model which is based on an improved score function for detecting an early failure in machines. In this study, the main focus will be the component interaction failures.

Several different techniques have been discussed in the literature for detecting failures and for failure analysis in machines. Zuber \& Bajri [2] applied artificial neural network and vibration analysis for automated roller element bearings faults identification, by using the vibration features as the inputs for the supervised artificial neural network. Sharma et al. [7]severity (S, using an integrated fuzzy logic and expert database evaluates system safety and reliability while conducting a failure mode and effect analysis (FMEA), they prioritize the failures which they used in taking corrective actions in a hydraulic system. Shaghaghi \& Rezaie [8] uses a generalized mixture operator to determine and aggregate risk priorities of failure modes in an LGS gas type circuit breaker product. Kangavari et al. [8], applied FMEA method to analyze risks of systems in the petrochemical industry from the concept phase to the system disposal, detecting the failures in the design stage and determining the control measures and corrective actions for failures to reduce their impact. Cebi et al. [10], applies an expert failure detection system to aid shipboard personnel to anticipate and overcome failures in operational ship auxiliary machinery by using a PROLOG programming language. They take into account the failure types that have already been identified and develop corrective action tables to demonstrate what to do in the event of an emergency.

In the effort to determine the risk priorities of failure modes and to select the most serious failure modes, Liu et al. [11], extended the VIKOR method under a fuzzy environment to address some limitations in the traditional FMEA method. Liu et al. [12], present an FMEA method which uses fuzzy evidential reasoning (FER) approach and grey theory for solving the diversity and expertise issues in the FMEA team assessment which is mainly due to the cross-functional and multidisciplinary nature of the team members and for solving the several shortcomings in the traditional FMEA approach as well as to improve the effectiveness of the traditional FMEA.

Alarcin et al. [13], using an integrated FAHP and TOPSIS methods, examine failure detection in an auxiliary system and marine diesel engine using groups of expert's opinions, by evaluating the expert's group's opinions, the system most affected by failures was determined. While He et al. [14], using Fuzzy TOPSIS and Rough set based approach identifies product infant failures that are most critical to improving product quality. By breaking down the early fault symptoms identified into root causes of critical functional parameters in the function domain, design parameters in the physical domain and process parameters in the manufacturing domain.

In this paper, we are aimed to present an Intuitionistic Fuzzy TOPSIS model which is based on an improved score function for detecting early failure in an offshore patrol boat engine, with special regards to component interaction accidents and failure, using groups of experts opinions to detect the root cause of failure and the system most affected by failures in the boat engine. In this respect, the failure in the engine is determined and prioritized, according to the section/systems in which the failures primarily arise. In this approach, the FSE method is used to determine the influential weights for the criteria while the Intuitionistic Fuzzy TOPSIS model is used to detect the root cause and area most affected by the failure in the locally made engine.

The choice of using intuitionistic fuzzy set in this study is based on the fact that it is more capable than the traditional fuzzy sets at handling vagueness and uncertain information in practice [15]. Also, introducing the Fuzzy TOPSIS model in an intuitionistic fuzzy environment by using improved score function based separation method provides a whole new approach to solving multi-criteria decision-making problem. The intuitionistic fuzzy set (IFS) was introduced by Atanassov [16], unlike the traditional fuzzy set theory, the IFS theory is characterized by a membership function and a non-membership function. The benefits of its applications have been addressed in [17]-[20].

The rest of this paper is organized as follows. Section 2 presents the concepts of Intuitionistic Fuzzy Set theory and the improved score function, introduction of the FSE method and Intuitionistic Fuzzy TOPSIS algorithm is presented in section 3. Section 4 contains a numerical case presented to explain the proposed methodology. Finally, the conclusions and further works are presented in section 5 .

\section{PRELIMINARIES}

In this section, the fundamental definitions and concepts of IFS theory are introduce as well as the improved score function as it relates to the IVIFS.

Definition 1

Let $\mathrm{D}[0,1]$ be the set of all closed subintervals of the interval $[0,1]$ and let $\mathrm{X}(\neq \emptyset)$ be a given set. An IVIFS $A$ in $X$ is expressed as [21];

$$
A=\left\{\left\langle x, \mu_{A}(x), v_{A}(x)\right\rangle \mid x \in X\right\},
$$

where $\mu_{A}: X \rightarrow \mathrm{D}[0,1], v_{A}: X \rightarrow \mathrm{D}[0,1]$ with the condition $0 \leq \sup \mu_{A}(x)+\sup v_{A}(x) \leq 1, \forall x \in X$.

The intervals $\mu_{A}(x)$ and $v_{A}(x)$ denote, respectively, the degree of membership and non-membership of the element $\mathrm{x}$ to the set A. Thus, for each $x \in X$ the intervals $\mu_{A}(x)$ and $v_{A}(x)$ are closed and their lower and upper end points are denoted by $\mu_{A L}(x), \mu_{A U}(x), v_{A L}(x)$ and $v_{A u}(x)$ respectively. One can denote the set as; 
$A=\left\{\left\langle x,\left[\mu_{A L}(x), \mu_{A U}(x)\right],\left[v_{A L}(x), v_{A U}(x)\right]\right\rangle \mid x \in X\right\}$,

Where, $0 \leq \mu_{A U}(x)+v_{A U}(x) \leq 1, \mu_{A L}(x) \geq 0$,

$v_{A L}(x) \geq 0$

For each element $x$, we can compute the unknown degree (hesitancy degree) of an intuitionistic fuzzy interval of $x \in X$ in $A$ which is defined as follows:

$$
\begin{aligned}
& \pi_{A}(x)=1-\mu_{A}(x)-v_{A}(x)=\left[1-\mu_{A L}(x)-\right. \\
& \left.\mu_{A U}(x), 1-\mu_{A L}(x)-v_{A L}(x)\right]
\end{aligned}
$$

However, if $\mu_{A}(x)=\mu_{A L}(x)=\mu_{A U}(x)$ and $v_{A}(x)=v_{A L}(x)=v_{A U}(x)$, then the given IVIFS A is reduced to an ordinary IFS. For convenience, the IVIFS can also be expressed as $A=([a, b],[c, d])$.

In order to make comparisons between two IVIFSs, metric methods have been introduced by several researchers [22] [23]. However, this study will focus on the improved score function originally proposed by Bai [21], for the ranking, and the representation of the aggregated effect of positive and negative evaluations in the performance ratings of the alternatives based on IVIFS data in the M-TOPSIS model. The computation formula for the improved score function is given as;

$$
I(A)=\frac{a+a(1-a-c)+b+b(1-b-d)}{2}, \text { where } I(A) \in[0,1]
$$

When $a=b$ and $c=d$, the IVIFS will degenerate to the IFS while the improved score function of IVIFS will degenerate to the score function of IFS proposed in [23].

\section{INTERVAL-VALUED INTUITIONISTIC FUZZY TOPSIS AND FUZZY SHANNON'S ENTROPY}

In this section, the concept of the FSE method and Intuitionistic Fuzzy TOPSIS algorithm proposed herein is introduced and the framework for the proposed model is given in Fig 1.

\section{FUZZY SHANNON'S ENTROPY}

The Shannon's entropy concept can be described as a general measure of uncertainty in the information formation in terms of probability theory [24]. The concept has a dominant role in information theory [25]. According to Saad et al. [26], Shannon's entropy concept is 'appropriate for calculating the relative contrast intensities of criteria to represent the average intrinsic information transmitted to the decision maker'.

The Shannon's entropy method which was extended by Lotfi \& Fallahnejad [27] for imprecise data, especially for interval and fuzzy data case, has found application in several fields of studies including, management, engineering, information sciences, agricultural sciences etc. and has prominently been used in the determination of criteria weight. The implementation steps are explained below.
In computing criteria weight using the fuzzy Shannon's entropy weight method in this study, first, a decision matrix is formed for the criteria to express the level of importance of each of the criterion using linguistic variables, and are later converted to the interval values and then to crisp value, the procedure are explained in the steps below;

Step 1. Normalized each of the criteria to obtain the projection value $\tilde{P}_{i j}$;

$$
\tilde{P}_{i j}=\frac{x_{i j}}{\sum_{i=0}^{m} x_{i j}}
$$

where $i=1, \ldots, m, j=1, \ldots, n$.

Step 2. Compute the entropy values $E p_{j}$;

$$
E p_{j}=-k \sum_{i=0}^{m} \tilde{P}_{i j} \operatorname{In} \tilde{P}_{i j}, \quad j=1, \ldots, n
$$

where $k$ is constant and is defined as $k=(\operatorname{In} m)^{-1}$, if $P_{i j}=0$, then $P_{i j} \operatorname{In} P_{i j}=0$

Step 3. Compute the degree of diversification, $d_{j}$ and finally the criteria weight $w_{j}$;

$$
\begin{gathered}
d_{j}=1-E p_{j}, \quad j=1, \ldots, n \\
w_{j}=\frac{d_{j}}{\sum_{k=1}^{n} d_{k}}
\end{gathered}
$$

\section{INTUITIONISTIC FUZZY TOPSIS MODEL}

TOPSIS model which is an abbreviation of Technique for Order Preference by Similarity to the Ideal Solution was originally proposed by Hwang \& Yoon [28] and has remained one of the most widely used MCDM methods with so many papers published on its applications and in several different fields of study including Accounting [29], Management [30] [31], Agriculture [32], Chemical science [33], Design [34], Business [35], Engineering [36][37], etc.

In this study, the TOPSIS model is introduced in the intuitionistic fuzzy environment, and an improved score function-based separation method is used for computing each alternative from the positive ideal solution and the negative ideal solutions. The Intuitionistic Fuzzy TOPSIS model and the FSE method above are expressed concisely using the following steps: 


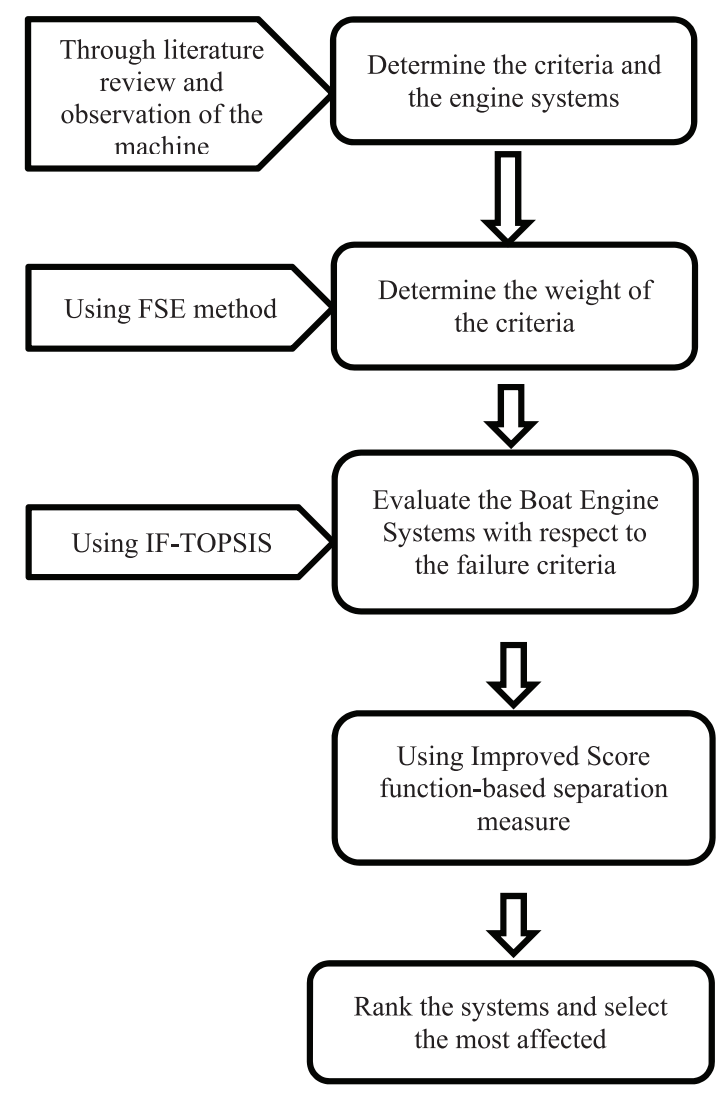

Fig1. The framework for the proposed model

Step 1. Set up a group of Decision Makers (DMs). With their opinion construct the intuitionistic fuzzy decision matrix $A_{n x m}\left(a_{i j}\right)$ of the alternatives $\left(A_{i}\right)$ with respect to the criteria $\left(C_{i}\right)$

$$
\begin{aligned}
& D_{m x n}\left(x_{i j}\right)= \\
& {\left[\begin{array}{cccc}
\left(\left[a_{11}, b_{11}\right],\left[c_{11}, d_{11}\right]\right) & \cdots & \cdots & \left(\left[a_{1 n}, b_{1 n}\right],\left[c_{1 n}, d_{1 n}\right]\right) \\
\left(\left[a_{21}, b_{21}\right],\left[c_{21}, d_{21}\right]\right) & \cdots & \cdots & \left(\left[a_{2 n}, b_{2 n}\right],\left[c_{2 n}, d_{2 n}\right]\right) \\
\vdots & \vdots & \ddots & \vdots \\
\vdots & \vdots & \ddots & \vdots \\
\left(\left[a_{m 1}, b_{m 1}\right],\left[c_{m 1}, d_{m 1}\right]\right) & \cdots & \cdots & \left(\left[a_{m n}, b_{m n}\right],\left[c_{m n}, d_{m n}\right]\right)
\end{array}\right]}
\end{aligned}
$$

Note: The weight of all the DMs are the same (i.e. DMs=1)

Step 2. Convert the intuitionistic fuzzy decision matrix $A_{n x m}\left(a_{i j}\right)$ to the improved score function matrix $I\left(a_{i j}\right)_{n x m}$;

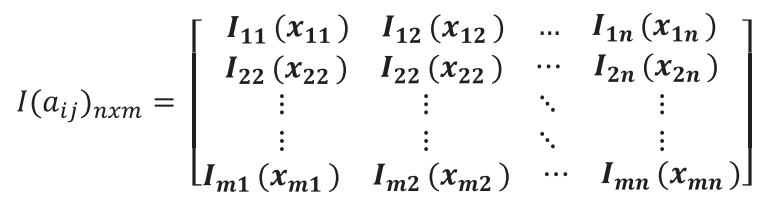

(10)

Step 3. Determine the weight of each of the evaluating criteria $w_{j}$ using the Shannon's entropy concept as described in section 3.1. Data are gathered using the Triangular Fuzzy Numbers for approximating the linguistic variable as shown in Table 1.
Tab. I. Intuitionistic Fuzzy Numbers for approximating the linguistic variable

\begin{tabular}{|c|c|c|}
\hline $\begin{array}{c}\text { Linguistic } \\
\text { terms }\end{array}$ & $\begin{array}{c}\text { Interval-valued } \\
\text { intuitionistic fuzzy } \\
\text { Number }\end{array}$ & $\begin{array}{c}\text { Triangular Fuzzy } \\
\text { Numbers (TFN) }\end{array}$ \\
\hline Very low (VL) & $\begin{array}{c}([0.1,0.3], \\
[0.25,0.4])\end{array}$ & $(0.1,0.25,0.3)$ \\
\hline Low (L) & $\begin{array}{c}([0.2,0.55], \\
[0.3,0.55])\end{array}$ & $(0.2,0.3,0.55)$ \\
\hline Good $(G)$ & $\begin{array}{c}([0.3,0.6], \\
[0.45,0.65])\end{array}$ & $(0.3,0.45,0.6)$ \\
\hline High $(\mathrm{H})$ & $\begin{array}{c}([0.5,0.7], \\
[0.6,0.7])\end{array}$ & $(0.6,0.75,0.9)$ \\
\hline Excellent & $\begin{array}{c}([0.6,0.9], \\
[0.75,1.0])\end{array}$ \\
\hline
\end{tabular}

Step 4. Define the Positive Ideal Solution $\left(A^{+}\right)$and Negative Ideal Solution $\left(A^{-}\right)$for the score function-based matrix; $A^{+}=\left(\mu_{j}, v_{j}\right), A^{-}=\left(\mu_{j}, v_{j}\right)$,

$$
\begin{aligned}
& A^{+}=(1,1), \quad j=1, \ldots, n \\
& A^{-}=(0,0), \quad j=1, \ldots, n
\end{aligned}
$$

Step 5. Compute the improved score function-based separation measures in intuitionistic fuzzy environment $\left(d^{+}{ }_{i}\left(A^{+}, A_{i}\right)\right.$ and $\left(d^{-}{ }_{i}\left(A^{-}, A_{i}\right)\right.$ for each alternative from the positive ideal and negative ideal solutions using the equation (13) and (14);

$$
d^{-}{ }_{i}\left(A^{-}, A_{i}\right)=\sqrt{\sum_{i=1}^{n}\left[w_{j}\left(1-\left(I\left(a_{i j}\right)_{n x m}\right)\right]^{2}\right.}
$$

Similarly,

$$
d^{-}{ }_{i}\left(A^{-}, A_{i}\right)=\sqrt{\sum_{i=1}^{n}\left[w_{j} I\left(a_{i j}\right)_{n x m}\right]^{2}}
$$

Step 7. Compute the relative closeness coefficient, $\left(C C_{i}\right)$, which is defined to rank all possible alternatives with respect to the positive ideal solution $A^{+}$. The general formula is given as;

$$
C C_{i}=\frac{d^{-}{ }_{i}\left(A^{-}, A_{i}\right)}{d^{-}{ }_{i}\left(A^{-}, A_{i}\right)+d^{+}{ }_{i}\left(A^{+}, A_{i}\right)}
$$

where $C C_{i}(i=1,2, \ldots n)$ is the relative closeness coefficient of $A_{i}$ with respect to the positive ideal solution $A^{+}$and $0 \leq C C_{i} \leq 1$. Hence, the alternatives are ranked according to the descending order.

\section{APPLICATION OF THE FSE METHOD AND INTUITIONISTIC FUZZY TOPSIS MODEL}

In this section, the computational process of the Fuzzy Shannon's entropy and Intuitionistic Fuzzy TOPSIS algorithm proposed herein in detecting an early failure in a locally made offshore patrol boat engine will be demonstrated. 
Case 1. Failure in the machine can results in severe damage and significant loss of resources when not detected on time. The severity levels of most of the faults in machines are mostly different. Some of the failures/faults can be so severe that if not detected and adjusted on time, they can cause more serious accidents as in the case of component failure during operational conditions.

Causes and symptoms of failures in machines are often precursors of further breakdown and cannot be found instantly but during the operational conditions. Probable breakdown/failure in such machines can be diagnosed using the traditional failure detection mechanism (sensor) [38]. However, pinpointing the exact problem, the root causes and the area most affected by failure still remains an issue. Criteria to evaluate such probable breakdown/failure, in this case, a locally made offshore patrol boat engine have been investigated and obtained through extended consultation from a group of experts mostly professors in the department of Mechanical Engineering. They were asked to rate the relevance, accuracy, and adequacy of the criteria and subcriteria and to confirm 'content validity' with regards to the operation of the boat engine assessment.

Five probable failures (criteria) in the engine systems [13], [18] have been identified and they are consolidated with the experience and opinions of the experts, these criteria and their subs-criteria include;

- Engine turns but does not fire $\left(\mathrm{C}_{1}\right)$. This criterion includes the following sub-criteria, Engine cabling $\left(C_{11}\right)$, Fuel system $\left(C_{12}\right)$, Engine governor $\left(C_{13}\right)$, Starter $\left(\mathrm{C}_{14}\right)$.

- $\quad$ Engine speed not steady $\left(\mathrm{C}_{2}\right)$. This criterion includes the following sub-criteria, Fuel system $\left(\mathrm{C}_{21}\right)$, Engine governor $\left(\mathrm{C}_{22}\right)$, Fuel injection equipment $\left(\mathrm{C}_{23}\right)$, and Speed sensor $\left(\mathrm{C}_{24}\right)$.

- Sudden shut down of the engine during normal operation $\left(\mathrm{C}_{3}\right)$. Low-level day tank $\left(\mathrm{C}_{31}\right)$, Low Oil pressure $\left(\mathrm{C}_{32}\right)$, and High-Pressure Fuel pump failures $\left(\mathrm{C}_{33}\right)$

- Black exhaust gas $\left(\mathrm{C}_{4}\right)$ Air supply $\left(\mathrm{C}_{41}\right)$, Fuel injection equipment $\left(\mathrm{C}_{42}\right)$,

- Increase of the oil level during engine operation $\left(\mathrm{C}_{5}\right)$ Cooling water leakage $\left(\mathrm{C}_{51}\right)$, and Fuel oil leakage $\left(\mathrm{C}_{52}\right)$

These failures are recognized to have a relationship with different systems in the engine. Hence, the root cause of these failures is determined based on these systems and they categorized as:

- Air supply System $\left(\mathrm{A}_{1}\right)$

- Fuel System $\left(\mathrm{A}_{2}\right)$,

- Engine Governor System $\left(\mathrm{A}_{3}\right)$,

- Engine Coolant System $\left(\mathrm{A}_{4}\right)$.

Using the assessment report from the group of experts on the boat engine, the proposed FSE method and Intuitionistic Fuzzy TOPSIS model is implemented. Summary of the implementation is given below.
Step 1: Construct the intuitionistic fuzzy decision matrix; the study uses the intuitionistic fuzzy number in Table 1 to express the ratings of the four systems with respect to each of the criteria and sub-criteria to form the intuitionistic fuzzy decision matrix $A_{n x m}\left(a_{i j}\right)$ as shown in Table 2.

Step 2: Using the improved score function, the intuitionistic fuzzy decision matrix $A_{n x m}\left(a_{i j}\right)$ is converted to form the improved score function matrix $I\left(a_{i j}\right)_{n x m}$; (i.e. equation (10)) as show in the Table 3. Also, by following the implementation procedure for the FSE method, the weights of the criteria are determined and the results for criteria weights are shown in Table 3.

By using equation (13) and (14), we compute the Modified exponential score function-based separation measures $\left(d^{+}{ }_{i}\left(A^{+}, A_{i}\right)\right.$ and $\left(d^{-}{ }_{i}\left(A^{-}, A_{i}\right)(i=1,2,3,4)\right.$, the results are as follows;

$$
\begin{aligned}
& \left(d^{+}{ }_{1}\left(A^{+}, A_{1}\right)=0.385,\left(d^{-}{ }_{1}\left(A^{-}, A_{1}\right)=0.296\right.\right. \\
& \left(d^{+}{ }_{2}\left(A^{+}, A_{2}\right)=0.401,\left(d^{-}{ }_{2}\left(A^{-}, A_{2}\right)=0.283,\right.\right. \\
& \left(d^{+}{ }_{3}\left(A^{+}, A_{3}\right)=0.395, \quad\left(d^{-}{ }_{3}\left(A^{-}, A_{3}\right)=0.286,\right.\right. \\
& \left(d^{+}{ }_{4}\left(A^{+}, A_{4}\right)=0.399, \quad\left(d^{-}{ }_{4}\left(A^{-}, A_{4}\right)=0.280 .\right.\right.
\end{aligned}
$$

Finally, the results for the relative closeness coefficient $C C_{i},(i=1,2,3,4)$ to the ideal solution which is calculated using equation (15) is given as;

$$
\begin{aligned}
& C C_{1}=0.435, C C_{2}=0.414, C C_{3}=0.420 \text { and } C C_{4}= \\
& 0.412,
\end{aligned}
$$

Therefore, the ranking orders for the four systems are in the form (descending order) $A_{1}>A_{3}>A_{2}>A_{4}$, obviously, from the evaluation of the boat engine system, the Air Supply system $A_{1}$ is the most affected area of engine considering the assessment given by the experts, followed by the Engine Governor System etc. 
Table 2. Intuitionistic fuzzy decision matrix

\begin{tabular}{|c|c|c|c|c|}
\hline & $\begin{array}{c}\text { Air supply System } \\
\qquad\left(A_{1}\right)\end{array}$ & $\begin{array}{l}\text { Fuel System } \\
\qquad\left(\mathrm{A}_{2}\right)\end{array}$ & $\begin{array}{c}\text { Governor System } \\
\qquad\left(\mathrm{A}_{3}\right)\end{array}$ & Coolant System $\left(\mathrm{A}_{4}\right)$ \\
\hline $\mathrm{C}_{1}$ & $([0.20,0.48],[0.33,0.53])$ & $([0.40,0.65],[0.50,0.65])$ & $([0.30,0.53],[0.43,0.58])$ & $([0.20,0.48],[0.33,0.53])$ \\
\hline $\mathrm{C}_{11}$ & $([0.37,0.57],[0.48,0.6])$ & $([0.47,0.80],[0.65,0.88])$ & $([0.43,0.72],[0.55,0.70])$ & $([0.20,0.48],[0.33,0.53])$ \\
\hline $\mathrm{C}_{12}$ & $([0.43,0.67],[0.55,0.85])$ & $([0.27,0.58],[0.4,0.60])$ & $([0.17,0.47] .[0.28,0.75])$ & $([0.20,0.48],[0.33,0.63])$ \\
\hline $\mathrm{C}_{13}$ & $([0.33,0.62],[0.45,0.68])$ & $([0.37,0.63],[0.50,0.62])$ & $([0.33,0.62],[0.45,0.78])$ & $([0.23,0.57],[0.35,0.53])$ \\
\hline $\mathrm{C}_{14}$ & $([0.30,0.53],[0.43,0.63])$ & $([0.53,0.77],[0.65,0.68])$ & $([0.30,0.58],[0.43,0.50])$ & $([0.37,0.63],[0.50,0.58])$ \\
\hline $\mathrm{C}_{2}$ & $([0.27,0.52],[0.38,0.58])$ & $([0.53,0.77],[0.65,0.90])$ & $([0.23,0.57],[0.63,0.35])$ & $([0.43,0.67],[0.55,0.67])$ \\
\hline $\mathrm{C}_{21}$ & $([0.43,0.72],[0.55,0.55])$ & $([0.43,0.70],[0.58,0.65])$ & $([0.37,0.63],[0.58,0.50])$ & $([0.33,0.62],[0.45,0.67])$ \\
\hline $\mathrm{C}_{22}$ & $([0.37,0.57],[0.48,0.78)$ & $([0.37,0.57],[0.48,0.88])$ & $([0.17,0.40],[0.32,0.67])$ & $([0.23,0.50],[0.38,0.63])$ \\
\hline $\mathrm{C}_{23}$ & $([0.30,0.58],[0.43,0.6])$ & $([0.47,0.78],[0.60,0.60])$ & $([0.20,0.55],[0.30,0.48])$ & $([0.40,0.65],[0.50,0.57])$ \\
\hline $\mathrm{C}_{24}$ & $([0.33,0.62],[0.45,0.65])$ & $([0.37,0.57],[0.48,0.85])$ & $([0.30,0.60],[0.45,0.55])$ & $([0.47,0.73],[0.60,0.65])$ \\
\hline $\mathrm{C}_{3}$ & $(0.30,0.58],[0.43,0.63])$ & $([0.10,0.30],[0.25,0.60])$ & $([0.23,0.43],[0.37,0.65])$ & $([0.43,0.67],[0.55,0.78])$ \\
\hline $\mathrm{C}_{31}$ & $(0.40,0.65],[0.50,0.58])$ & $([0.27,0.58],[0.40,0.68])$ & $([0.33,0.62],[0.45,0.60])$ & $([0.37,0.68],[0.50,0.73])$ \\
\hline $\mathrm{C}_{32}$ & $([0.43,0.72],[0.55,0.55])$ & $([0.43,0.67],[0.55,0.67])$ & $([0.37,0.57],[0.48,0.78])$ & $([0.30,0.53],[0.43,0.63])$ \\
\hline $\mathrm{C}_{33}$ & $([0.37,0.57],[0.48,0.78])$ & $([0.40,0.65],[0.50,0.58])$ & $([0.33,0.62],[0.45,0.60])$ & $([0.37,0.63],[0.50,0.62])$ \\
\hline $\mathrm{C}_{4}$ & $([0.20,0.48],[0.33,0.53])$ & $([0.43,0.67],[0.55,0.67])$ & $([0.40,0.65],[0.50,0.58])$ & $([0.20,0.48],[0.33,0.53])$ \\
\hline $\mathrm{C}_{41}$ & $([0.33,0.62],[0.45,0.60])$ & $([0.43,0.72],[0.55,0.55])$ & $([0.43,0.67],[0.55,0.67])$ & $([0.40,0.65],[0.50,0.58])$ \\
\hline $\mathrm{C}_{42}$ & $([0.43,0.67],[0.55,0.67])$ & $([0.30,0.53],[0.43,0.63])$ & $([0.37,0.63],[0.50,0.62])$ & $([0.37,0.57],[0.48,0.78])$ \\
\hline $\mathrm{C}_{5}$ & $([0.43,0.72],[0.55,0.55])$ & $([0.20,0.48],[0.33,0.53])$ & $([0.33,0.62],[0.45,0.60])$ & $([0.30,0.53],[0.43,0.63])$ \\
\hline $\mathrm{C}_{51}$ & $([0.30,0.53],[0.43,0.63])$ & $([0.37,0.57],[0.48,0.78])$ & $([0.20,0.48],[0.33,0.53])$ & $(0.30,0.53],[0.43,0.63])$ \\
\hline $\mathrm{C}_{52}$ & $([0.65,0.50],[0.65,0.30])$ & $([0.72,0.55],[0.70,0.20])$ & $([0.37,0.60],[0.50,0.58])$ & $([0.20,0.48],[0.33,0.53])$ \\
\hline
\end{tabular}

Table 3. Modified exponential score matrix and criteria weights

\begin{tabular}{|c|c|c|c|c|c|}
\hline & $\begin{array}{c}\text { Air supply System } \\
\left(\mathrm{A}_{1}\right)\end{array}$ & $\begin{array}{l}\text { Fuel System } \\
\qquad\left(\mathrm{A}_{2}\right)\end{array}$ & $\begin{array}{c}\text { Governor System } \\
\left(\mathrm{A}_{3}\right)\end{array}$ & Coolant System $\left(\mathrm{A}_{4}\right)$ & Weight \\
\hline $\mathrm{C}_{1}$ & $(0.385)$ & $(0.448)$ & $(0.426)$ & $(0.385)$ & 0.156 \\
\hline $\mathrm{C}_{11}$ & $(0.449)$ & $(0.335)$ & $(0.428)$ & $(0.385)$ & 0.185 \\
\hline $\mathrm{C}_{12}$ & $(0.380)$ & $(0.417)$ & $(0.315)$ & $(0.361)$ & 0.152 \\
\hline $\mathrm{C}_{13}$ & $(0.418)$ & $(0.445)$ & $(0.387)$ & $(0.420)$ & 0.155 \\
\hline $\mathrm{C}_{14}$ & $(0.413)$ & $(0.429)$ & $(0.457)$ & $(0.455)$ & 0.125 \\
\hline $\mathrm{C}_{2}$ & $(0.416)$ & $(0.344)$ & $(0.439)$ & $(0.440)$ & 0.145 \\
\hline $\mathrm{C}_{21}$ & $(0.482)$ & $(0.440)$ & $(0.468)$ & $(0.421)$ & 0.128 \\
\hline $\mathrm{C}_{22}$ & $(0.398)$ & $(0.370)$ & $(0.314)$ & $(0.377)$ & 0.135 \\
\hline $\mathrm{C}_{23}$ & $(0.428)$ & $(0.460)$ & $(0.417)$ & $(0.474)$ & 0.146 \\
\hline $\mathrm{C}_{24}$ & $(0.428)$ & $(0.378)$ & $(0.443)$ & $(0.445)$ & 0.135 \\
\hline $\mathrm{C}_{3}$ & $(0.420)$ & $(0.248)$ & $(0.359)$ & $(0.404)$ & 0.146 \\
\hline $\mathrm{C}_{31}$ & $(0.470)$ & $(0.394)$ & $(0.443)$ & $(0.410)$ & 0.175 \\
\hline $\mathrm{C}_{32}$ & $(0.482)$ & $(0.440)$ & $(0.398)$ & $(0.413)$ & 0.156 \\
\hline $\mathrm{C}_{33}$ & $(0.398)$ & $(0.470)$ & $(0.443)$ & $(0.445)$ & 0.135 \\
\hline $\mathrm{C}_{4}$ & $(0.385)$ & $(0.440)$ & $(0.470)$ & $(0.385)$ & 0.166 \\
\hline $\mathrm{C}_{41}$ & $(0.443)$ & $(0.482)$ & $(0.440)$ & $(0.470)$ & 0.146 \\
\hline $\mathrm{C}_{42}$ & $(0.440)$ & $(0.413)$ & $(0.445)$ & $(0.398)$ & 0.154 \\
\hline $\mathrm{C}_{5}$ & $(0.482)$ & $(0.385)$ & $(0.443)$ & $(0.413)$ & 0.165 \\
\hline $\mathrm{C}_{51}$ & $(0.413)$ & $(0.398)$ & $(0.385)$ & $(0.413)$ & 0.159 \\
\hline $\mathrm{C}_{52}$ & $(0.528)$ & $(0.553)$ & $(0.455)$ & $(0.385)$ & 0.155 \\
\hline
\end{tabular}




\section{CONCLUSIONS}

Failure warnings and measures such as heating, pressure, and flow rate sensors as well as vibration measurement and analysis, motor current signature analysis, noise measurement, wear particle analysis, infrared thermography and ultrasound measurements devices are available and often used to detect and monitor possible failure in machines. However, early detection of such failures is still quite difficult to determine because of the dependency of the machine systems on each other.

In this paper, the authors investigated the application of an intuitionistic fuzzy multi-criteria decision-making method in detecting early failure in an offshore patrol boat engine, with special regards to component interaction accidents and failure, using groups of expert's opinions to detect the root cause of failure and the system most affected by failures in the boat engine. In this respect, the failure in the engine was determined and prioritized, according to the section/systems in which the failures primarily arise. In this approach, the Fuzzy Shannon's entropy method was used to determine the influential weights for the criteria while the Intuitionistic Fuzzy TOPSIS model which is based on an improved score function was used to detect the root cause and area most affected by the failure in the engine.

The application of the Fuzzy Shannon's entropy method and an Intuitionistic Fuzzy TOPSIS methodology in this study have proved that failures and faults, as well as their root cause in machines components, can be easily identified using expert's opinion. It provides an alternative to the computerbased generated fault diagnosis systems which use fault codes that cannot exactly pinpoint the actual problem in the machine and rather bring up an array of codes that could be either this or that.

Finally, the study has been able to provide a better alternative method for product development failure mode identification and analysis which hinder-to are limited when it comes to failure as a result of component interaction accidents. The results from the study show that the most affected system in the offshore patrol boat engine made is the Air Supply System follow by the Engine Governor System etc. based on the assessment of the experts.

\section{REFERENCES}

1. P. Kettunen, "Troubleshooting Large-Scale New Product Development Embedded Software Projects," in ProductFocused Software Process Improvement, vol. 4034, Elsevier B.V., 2006, pp. 61-78.

2. N. Zuber and R. Bajri, "Application of artificial neural networks and principal component analysis on vibration signals for automated fault classification of roller element bearings," Eksploat. i Niezawodn. - Maint. Reliab., vol. 18, no. 2, pp. 299-306, 2016.
3. A. Balin, H. Demirel, and F. Alarcin, "A Hierarchical Structure for Ship Diesel Engine Trouble-Shooting Problem Using Fuzzy Ahp and Fuzzy Vikor Hybrid Methods," Brodogradnja, vol. 66, no. 1, pp. 54-65, 2015.

4. D. O. Aikhuele and F. M. Turan, "Need for reliability assessment of parent product before redesigning a new product," Curr. Sci., vol. 112, no. 1, pp. 10-11, 2017.

5. J. A. Keizer, J.-P. Vos, and J. Halman, "Risks in New Product Development," 2005.

6. R. S. Martínez, "System Theoretic Process Analysis of Electric Power Steering for Automotive Applications," 2015.

7. R. K. Sharma, D. Kumar, and P. Kumar, "Systematic failure mode effect analysis (FMEA) using fuzzy linguistic modelling," Int. J. Qual. Reliab. Manag., vol. 22, no. 9, pp. 986-1004, 2005.

8. M. Shaghaghi and K. Rezaie, "Failure Mode and Effects Analysis Using Generalized Mixture Operators," J. Optim. Ind. Eng., vol. 11, pp. 1-10, 2012.

9. M. Kangavari, S. Salimi, R. Nourian, L. Omidi, and A. Askarian, "An application of failure mode and effect analysis ( FMEA ) to assess risks in petrochemical industry in Iran," Iran. J. Heal. Saf. Environ., vol. 2, no. 2, pp. 257263, 2015.

10. S. Cebi, M. Celik, C. Kahraman, and I. D. Er, “An expert system towards solving ship auxiliary machinery troubleshooting: SHIPAMTSOLVER," Expert Syst. Appl., vol. 36, no. 3 PART 2, pp. 7219-7227, 2009.

11. H.-C. Liu, L. Liu, N. Liu, and L.-X. Mao, "Risk evaluation in failure mode and effects analysis with extended VIKOR method under fuzzy environment," Expert Syst. Appl., vol. 39, no. 17, pp. 12926-12934, 2012.

12. H.-C. Liu, L. Liu, Q. Bian, Q. Lin, N. Dong, and P. Xu, "Failure mode and effects analysis using fuzzy evidential reasoning approach and grey theory," Expert Syst. Appl., vol. 38, no. 4, pp. 4403-4415, 2011.

13. F. Alarcin, A. Balin, and H. Demirel, "Fuzzy AHP and Fuzzy TOPSIS integrated hybrid method for auxiliary systems of ship main engines," J. Mar. Eng. Technol., vol. 13, no. 1, pp. 3-11, 2014.

14. Y.-H. He, L.-B. Wang, Z.-Z. He, and M. Xie, "A fuzzy TOPSIS and Rough Set based approach for mechanism analysis of product infant failure," Eng. Appl. Artif. Intell., vol. 47, pp. 1-13, 2015.

15. G. M. Saurav Datta, Chitrasen Samantra, Siba Sankar Mahapatra, Goutam Mondal, Partha Sarathi Chakraborty, 
"Selection of internet assessment vendor using TOPSIS method in fuzzy environment," Int. J. Bus. Perform. Supply Chain Model., vol. 5, no. 1, pp. 1-27, 2013.

16. K. T. Atanassov, "Intuitionistic fuzzy sets," Fuzzy Sets Syst., vol. 20, no. 1, pp. 87-96, 1986.

17. Z. Xu and H. Liao, "A survey of approaches to decision making with intuitionistic fuzzy preference relations," Knowledge-Based Syst., vol. 80, pp. 131-142, 2015.

18. D. O. Aikhuele and F. M. Turan, "A modified exponential score function for troubleshooting an improved locally made Offshore Patrol Boat engine," J. Mar. Eng. Technol., vol. 4177, no. February, 2017.

19. Z. Xu, S. Member, and H. Liao, "Intuitionistic fuzzy analytic hierarchy process," IEEE Trans. Fuzzy Syst., vol. 22, no. 4, pp. 749-761, 2014.

20. D. O. Aikhuele and F. B. M. Turan, "An Improved Methodology for Multi-criteria Evaluations in the Shipping Industry," Brodogradnja/Shipbuilding, vol. 67, no. 3, pp. 59-72, 2016.

21. Z. Bai, "An Interval-Valued Intuitionistic Fuzzy TOPSIS Method Based on an Improved Score Function," Sci. World J., vol. 2013, pp. 1-9, 2013

22. D.-F. Li, "Multiattribute decision making method based on generalized OWA operators with intuitionistic fuzzy sets," Expert Syst. Appl., vol. 37, no. 12, pp. 8673-8678, 2010.

23. J. Ye, "Multicriteria fuzzy decision-making method based on a novel accuracy function under interval-valued intuitionistic fuzzy environment," Expert Syst. Appl., vol. 36, no. 3, pp. 6899-6902, 2009.

24. T. Wang, H. Lee, and C. Wu, "A Fuzzy TOPSIS Approach with Subjective Weights and Objective Weights," in 6th WSEAS International Conference on Applied Computer Science, 2007, pp. 1-6.

25. Ü. Şengül, M. Eren, S. Eslamian Shiraz, V. Gezder, and A. B. Şengül, "Fuzzy TOPSIS method for ranking renewable energy supply systems in Turkey," Renew. Energy, vol. 75, pp. 617-625, 2015.

26. R. Saad, M. Z. Ahmad, M. S. Abu, and M. S. Jusoh, "Hamming distance method with subjective and objective weights for personnel selection.," ScientificWorldJournal., vol. 2014 , p. $865495,2014$.

27. F. H. Lotfi and R. Fallahnejad, "Imprecise shannon's entropy and multi attribute decision making," Entropy, vol. 12, no. 1, pp. 53-62, 2010.
28. Hwang C. L. and Yoon K., Multiple Attribute Decision Making Methods and Applications. Berlin: Springer, 1981.

29. B. Bulgurcu, "Application of TOPSIS Technique for Financial Performance Evaluation of Technology Firms in Istanbul Stock Exchange Market," Procedia - Soc. Behav. Sci., vol. 62, pp. 1033-1040, 2012.

30. O. Jadidi, T. Hong, and F. Firouzi, "TOPSIS and fuzzy multi-objective model integration for supplier selection problem," J. Achiev. Mater. Manufactuing Eng., vol. 31, no. 2, pp. 762-769, 2008.

31. A. Azizi, D. O. Aikhuele, and F. S. Souleman, "A Fuzzy TOPSIS Model to Rank Automotive Suppliers," Procedia Manuf., vol. 2, no. February, pp. 159-164, 2015.

32. S. Pakpour, S. V Olishevska, S. O. Prasher, A. S. Milani, and M. R. Chénier, "DNA extraction method selection for agricultural soil using TOPSIS multiple criteria decisionmaking model,” Am. J. Mol. Biol., vol. Published, no. October, pp. 215-228, 2013.

33. M. D. Soufi, B. Ghobadian, G. Najafi, M. R. Sabzimaleki, and T. Yusaf, "TOPSIS multi-criteria decision modeling approach for biolubricant selection for two-stroke petrol engines," Energies, vol. 8, no. 12, pp. 13960-13970, 2015.

34. C. Yang and Q. Wu, "Decision Model for Product Design Based on Fuzzy TOPSIS Method," 2008 Int. Symp. Comput. Intell. Des., pp. 342-345, 2008.

35. M. Ghazanfari, S. Rouhani, and M. Jafari, "A fuzzy TOPSIS model to evaluate the Business Intelligence competencies of Port Community Systems," Polish Marit. Res., vol. 21, no. 2, pp. 86-96, 2014.

36. X. Zhu, F. Wang, C. Liang, J. Li, and X. Sun, "Quality credit evaluation based on TOPSIS: Evidence from airconditioning market in China," Procedia Comput. Sci., vol. 9, no. 10, pp. 1256-1262, 2012.

37. D. O. Aikhuele and F. B. M. Turan, "Intuitionistic fuzzybased model for failure detection," Springerplus, vol. 5, no. 1, p. 1938, 2016.

38. F. Lu, J. Huang, and Y. Xing, "Fault diagnostics for turboshaft engine sensors based on a simplified on-board model," Sensors (Switzerland), vol. 12, no. 8, pp. 11061-11076, 2012. 


\section{CONTACT WITH THE AUTHOR}

Daniel Osezua Aikhuele1, MSc

Faiz Mohd Turan, PhD

Faculty of Manufacturing Engineering

Universiti Malaysia Pahang 26600 Pekan

Shahryar Sorooshian, PhD

Richard Hannis Ansah, MSc

Faculty of Industrial Management Universiti Malaysia Pahang 26600 Pekan

Malaysia 